\title{
Mundos distintos e realidades semelhantes: empregabilidade dos jovens no Nordeste e Sudeste brasileiros
}

\author{
Mateus de Carvalho Reis Neves* \\ Marcos Falcão Gonçalves ${ }^{\star \star}$ \\ João Eustáquio de Lima**
}

\begin{abstract}
0 artigo aborda como certos fatores influenciaram a probabilidade da participação no mercado de trabalho de jovens de 15 a 24 anos, nas Regiões Nordeste e Sudeste, marcadas pela heterogeneidade entre si, em diversas dimensões. Para tanto, analisaram-se as razões de risco relativo e os efeitos marginais resultantes de uma função logística aplicada aos microdados da Pesquisa Nacional por Amostra de Domicílios - PNAD de 2012. Constatou-se que, a despeito das disparidades socioeconômicas presentes nestas regiões brasileiras, ambas exibiram comportamentos similares quanto ao efeito dos determinantes sobre a empregabilidade dos jovens. Ficou evidenciado que a escolaridade e a experiência profissional influenciam positivamente a participação no mercado de trabalho, sobretudo no Sudeste, onde um ano a mais de estudo eleva as chances de emprego em $16 \%$. Ser mulher possui relação negativa com a probabilidade de trabalhar, especialmente no Nordeste, tendo em vista que os jovens do sexo masculino têm o dobro de chances de estarem empregados. Ainda, os jovens brancos do Sudeste possuem $28 \%$ menos probabilidade de estarem trabalhando, em relação aos não brancos. Tais resultados sugerem o caminho que podem trilhar políticas públicas, específicas para cada região, que visem mitigar o desemprego entre os jovens.
\end{abstract}

Palavras-chave: Empregabilidade. Jovens. Função logística.

\footnotetext{
*Universidade Federal de Viçosa - UFV, Viçosa-MG, Brasil (mateus.neves@ufv.br).

** Universidade Federal de Viçosa - UFV, Viçosa-MG, Brasil (marcos.falcao@ufv.br).

${ }^{\star \star \star}$ Universidade Federal de Viçosa - UFV, Viçosa-MG, Brasil (jelima@ufv.br).
} 


\section{Introdução}

As transformações nos modelos de produção, em curso nos países ao redor do mundo, fazem com que o desemprego inscreva-se como uma marca estrutural de diversas sociedades contemporâneas, levando à indagação sobre a genealogia e a dimensão individual e coletiva dos processos em curso (GENNARI; ALBUQUERQUE, 2012). Ademais, Missio, Vieira e lahn (2008) preconizam que a busca por maior produtividade do trabalho tem induzido a diminuição da oferta de empregos e a ampliação da base de exigências qualitativas do trabalhador - maior escolarização e proatividade - para que este esteja apto a ocupar as novas funções que vão surgindo com a mudança da base tecnológica do sistema produtivo.

Sabe-se que entre os jovens concentra-se a maior parte dos indivíduos que buscam se incorporar ao mercado de trabalho pela primeira vez. ${ }^{1}$ Presente no contexto elucidativo acerca do elevado desemprego juvenil está justamente a dificuldade do jovem em obter o primeiro emprego. Ainda o desemprego juvenil é associado a um sistema de educação inadequado perante as já citadas, e cada vez maiores, exigências do mercado de trabalho e a incapacidade dos jovens em permanecer na escola. ${ }^{2}$ Outros autores, como Silva (2001), destacam a opção, por parte dos empresários, por trabalhadores adultos, que somam experiência e hábitos de trabalho mais sedimentados, tornando-se, portanto, mais um obstáculo aos jovens.

Entretanto, de acordo com Costanzi (2009), não existe apenas uma juventude no Brasil. A heterogeneidade e as desigualdades que permeiam a sociedade brasileira tornam-se manifestas na situação dos jovens, mormente quando se considera o acesso a direitos, bens e serviços, que ampliam ou restringem as possibilidades de acesso a um trabalho decente. Existem, de fato, juventudes diversas, imersas em distintos cenários. As mulheres jovens, os jovens negros de ambos os sexos, bem como os jovens das regiões de baixa renda, ou de zonas rurais, por vezes, são molestados de forma mais severa pela exclusão social, pela falta de oportunidades e pelo déficit de oportunidades de emprego de qualidade. ${ }^{3}$

Assim, investigar algumas características relativas à participação dos jovens no mercado de trabalho, considerando algumas das diversidades regionais brasileiras, torna-se relevante para a compreensão de peculiaridades que auxiliem na elaboração de ações no sentido de uma melhor adequação dos jovens aos postos de trabalho. Pretende-se, portanto, a partir de dados da Pesquisa Nacional por Amostra de Domicílios (PNAD) de 2012, analisar alguns fatores associados à participação de jovens, com idade entre 15 e

\footnotetext{
${ }^{1}$ A taxa de participação dos jovens de 15 a 24 anos, no Brasil, em 2006, era de 63,9\%. Isso significa que cerca de dois em cada três jovens estavam trabalhando ou buscando ativamente uma ocupação (COSTANZI, 2009).

2 A frequência ao ensino médio na idade adequada abrange, atualmente, menos da metade dos jovens brasileiros de 15 a 17 anos, tendo em vista que cerca de um terço deles ainda está no ensino fundamental e cerca de $18 \%$ estão fora da escola (CASTRO; AQUINO, 2008).

${ }^{3}$ Enquanto, em 2006, a taxa geral de desemprego (para os trabalhadores de 15 anos ou mais) era de $8,4 \%$ e a dos adultos correspondia a 5,6\%, para os jovens essa cifra se elevava a $17,8 \%$, sendo, portanto, aproximadamente 3,2 vezes superior à dos adultos e 2,1 vezes maior do que a taxa geral de desemprego (COSTANZI, 2009).
} 
24 anos, no mercado de trabalho de duas regiões brasileiras balizadas por grandes heterogeneidades socioeconômicas e demográficas: Sudeste e Nordeste. ${ }^{4}$

No Sudeste então circunscritos alguns dos maiores polos urbanos e industriais, responsáveis pela maior parte do Produto Interno Bruto nacional, sendo a região mais afetada pela reestruturação produtiva. Por outro lado, o Nordeste, segundo Lima (2008), caracteriza-se pela baixa elasticidade emprego-produto, maior vulnerabilidade às variações climáticas, menores níveis de escolarização, rendimento e qualificação e grandes áreas pouco integradas à economia nacional.

Assim, objetiva-se, com este estudo, examinar os diferenciais, entre as Regiões Nordeste e Sudeste, de determinados fatores demográficos e socioeconômicos relacionados à participação dos jovens de 15 a 24 anos no mercado de trabalho.

\section{Metodologia}

\section{Dados e variáveis}

Os dados utilizados neste estudo foram retirados da Pesquisa Nacional por Amostra de Domicílios (PNAD), baseada em amostra probabilística de domicílios, com abrangência nacional, realizada pelo Instituto Brasileiro de Geografia e Estatística (IBGE), em setembro de 2012 (IBGE, 2013a).

Conforme exposto por Leite e Silva (2002), a PNAD tem como finalidade produzir informações básicas, que possam ser empregadas no estudo de soluções que levem ao desenvolvimento do país. 0 plano amostral da pesquisa permite a obtenção de resultados para o total do Brasil, para cada uma das regiões geográficas e para cada estado brasileiro. Devido à natureza de sua coleta de dados, a pesquisa relata informações pormenorizadas acerca das condições socioeconômicas de cada um dos indivíduos residentes nos domicílios amostrados.

Tendo como escopo deste trabalho os jovens residentes nas Regiões Nordeste (NE) e Sudeste (SE) do país, de ambos os sexos, com idade entre 15 e 24 anos, obteve-se uma amostra composta por 33.750 indivíduos (18.113 no NE e 15.637 no SE).

\section{Fatores determinantes para participação no mercado de trabalho}

Para determinar a participação do jovem no mercado de trabalho, foram consideradas três categorias relacionadas à situação ocupacional na qual o jovem poderia situar-se, no ano analisado, respeitando os critérios descritos nas notas técnicas da PNAD (IBGE, 2013b): estar ativo e empregado, ativo e desempregado ou inativo. Na categoria ativos

\footnotetext{
${ }^{4}$ Uma ilustração desta realidade pode ser a taxa de analfabetismo que, embora seja residual para os jovens de 15 a 24 anos nas Regiões Sul, Sudeste e Centro-Oeste, tem sua erradicação ainda se constituindo um desafio para o Nordeste, onde a taxa é de $2,4 \%$, sendo ainda maior (3,3\%) no caso dos homens jovens, em 2012. Ademais, também em 2012, a taxa de informalidade do emprego, entre os jovens, era de $34 \%$ no Sudeste, enquanto no Nordeste chegava a quase $70 \%$ (IBGE, 2013a).
} 
e empregados, enquadram-se os jovens que estavam efetivamente trabalhando (em atividade remunerada ou não remunerada) no período de referência da PNAD de 2012, ou em parte dele (semana de referência ${ }^{5}$ ou período de referência de 365 dias). A categoria ativos e desempregados engloba aqueles que estavam desempregados, mas que tomaram providência na busca por emprego, também no período de referência. Por fim, inativos são os jovens que não estavam trabalhando e não haviam procurado emprego no período de referência. Vale destacar que nesta última categoria foram incluídos aqueles que estavam somente estudando, assim como os que realizavam afazeres domésticos sem remuneração.

A probabilidade de os jovens estarem em uma destas categorias varia de acordo com as mais diversas características. Alguns destes atributos observáveis foram selecionados para uso neste artigo e são descritos a seguir.

- Sexo - variável dummy que assume valor 1, quando o jovem é do sexo masculino, e 0 , caso seja do sexo feminino.

- Raça/cor - variável dummy que tem valor 1, quando o jovem é branco, e 0, caso contrário.

- Filho - variável dummy que adquire valor 1, quando o jovem está na posição de filho da família, e 0, caso contrário (a partir da informação da pessoa de referência na família).

- Cônjuge - variável dummy com valor 1 , quando o jovem está na condição de cônjuge na família, e 0, caso contrário (a partir da informação da pessoa de referência na família).

- Outro - variável dummy que assume valor 1, quando o jovem é outro parente, agregado, pensionista, empregado doméstico ou parente do empregado doméstico da pessoa de referência na família, e 0 , caso contrário.

- Chefe (categoria base) - variável dummy que tem valor 1, quando o jovem está na condição de pessoa de referência da família, e 0 , caso contrário.

- Situação de domicílio - variável dummy que apresenta valor 1 , quando o jovem reside no meio urbano, e 0 , caso resida no meio rural.

- Experiência - anos de experiência do jovem no mercado de trabalho, somados os períodos de experiência profissional no emprego anterior, caso haja, e no emprego atual, caso haja.

- Escolaridade - anos completos de estudo do jovem.

- Escolaridade $x$ experiência - interação das variáveis experiência e escolaridade.

- Componentes da família - número de componentes da família.

- Renda - logaritmo natural do rendimento total per capita da família (somado 1 para rendimento zero).

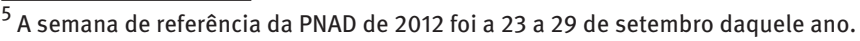


- Situação ocupacional - variável dependente, que tem valor 0 , quando o jovem pertence à categoria inativa, 1, caso o jovem seja ativo e empregado, e 2, se estiver na categoria ativo e desempregado.

\section{Método}

Almejou-se definir quais características, entre aquelas selecionadas, foram relevantes para a participação no mercado de trabalho dos jovens de ambos os sexos de 15 a 24 anos, ${ }^{6}$ ou seja, buscou-se observar quais atributos o jovem e seus familiares possuíam (sexo, raça/cor, condição na família, situação de domicílio, experiência, escolaridade, tamanho da família e renda familiar), tomando-os como fatores explicadores de sua relação com o mercado de trabalho em 2012. Além disso, procurou-se ressaltar as diversidades e similitudes regionais derivadas da comparação entre as Regiões Nordeste e Sudeste.

Aplicações similares de modelos na determinação da participação dos indivíduos na força de trabalho, para o Brasil, foram abordadas por Mendonça et al. (2012), Silva e Kassouf (2002), Kassouf (1999, 1998), Fernandes e Picchetti (1999), entre outros. 0 instrumental econométrico utilizado, que possibilitou investigar as probabilidades de inatividade, emprego e desemprego, foi o logit multinomial, adequado para análise de variáveis dependentes categóricas, com $J$ possíveis categorias, sem que haja alguma ordenação entre estas categorias. Desse modo, no modelo logit multinomial empregado, as categorias ocupacionais em que os jovens poderiam enquadrar-se foram definidas como: inativos $(j=0)$; ativos e empregados $(j=1)$; e ativos e desempregados $(j=2)$.

A estrutura destes modelos baseia-se na análise de probabilidades e, segundo Greene (2003), pode ser ilustrada na seguinte forma:

$P_{j}=\operatorname{Prob}(Y=j)=F\left(X^{\prime}, \beta\right)$

Onde $j$ corresponde às categorias em que o jovem pode se situar. 0 conjunto do parâmetro $\beta$ reflete o impacto das mudanças em $x$ (matriz de características observáveis dos jovens) na probabilidade de determinado jovem se encontrar em uma das três categorias possíveis.

Especifica-se o modelo logit multinomial, utilizado neste trabalho, como segue:

$P_{j}=\operatorname{Prob}\left(Y_{i}=j\right)=\frac{e^{\beta_{j}{ }^{\prime} x_{i}}}{\sum_{k=0}^{j} e^{\beta_{k}{ }^{\prime} x_{i}}}, j=0,1,2, \ldots J$

Onde $Y_{i}$ é a variável aleatória que indica a categoria ocupacional à qual o jovem pertence; $P_{j}$ corresponde à probabilidade de o evento $j$ ocorrer, o que é equivalente à probabilidade do jovem pertencer à categoria $j$; $x$ representa a matriz de atributos dos jovens; e $\beta$ refere-se ao vetor de parâmetros a ser estimado.

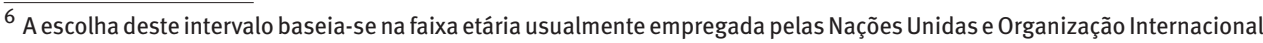
do Trabalho (2007) em estudos desta natureza, para motivos de comparabilidade. Entretanto, é importante salientar que a Constituição brasileira determina os 16 anos como idade mínima para o trabalho, admitindo, a partir dos 14 anos, apenas o trabalho na condição de aprendiz.
} 
Nesse sentido, conforme o modelo descrito, a probabilidade de que ocorra certa resposta, ou seja, que o indivíduo se enquadre em uma das três categorias de ocupação definidas, varia entre os jovens de acordo com seus atributos observados.

Deve-se salientar que especificar o modelo conforme a equação (2) geraria uma indeterminação, fato que pode ser resolvido escolhendo-se uma das formulações alternativas. Greene (2003) indica que uma normalização usual é supor igual a zero. Desse modo, as probabilidades seriam:

$P_{j}=\operatorname{Prob}\left(Y_{i}=j\right)=\frac{e^{\beta_{j}{ }^{\prime} x_{i}}}{1+\sum_{k=0}^{j} e^{\beta_{k}{ }^{\prime} x_{i}}}, j=0,1,2, \ldots J$

e

$P_{j}=\operatorname{Prob}\left(Y_{i}=0\right)=\frac{1}{1+\sum_{k=0}^{j} e^{\beta_{k}{ }^{\prime} x_{i}}}$

Neste trabalho, foi utilizado o método de Máxima Pseudoverossimilhança (MPV), tendo em vista características do plano amostral complexo da PNAD, ${ }^{7}$ implicando, diferentemente do método de Mínimos Quadrados Ordinários, por exemplo, coeficientes estimados que não possuem respostas marginais que possam ser assim interpretadas. Visando contornar esta limitação, foram calculados os efeitos marginais dos coeficientes, de modo a facilitar a avaliação dos resultados. Tais efeitos são obtidos pela diferenciação das equações (3) e (4): $\delta_{j}=\frac{\partial P_{j}}{\partial x_{i}}=P_{j}\left[\beta_{j}-\sum_{k=0}^{J} P_{k} \beta_{k}\right]=P_{j}\left[\beta_{j}-\bar{\beta}\right]$

Assim, de acordo com Greene (2003), os efeitos marginais são definidos conforme descrito na equação (5). Tem-se que todos os subvetores de $\beta$ captam cada efeito marginal, por meio tanto das probabilidades quanto da média ponderada definida em $\delta_{j}$. Esses valores podem ser computados a partir das estimativas dos parâmetros. Deve-se salientar que, para qualquer $x_{k}$ particular, $\delta P_{j} / \delta_{j} x_{k}$ pode não ter o mesmo sinal de $\beta_{j k}$, ou seja, 0 sinal dos efeitos marginais pode não ser o mesmo dos coeficientes estimados. ${ }^{8}$

É possível complementar a abordagem dos efeitos marginais por meio de uma forma alternativa de análise, conhecida como odds-ratio ou razão de risco relativo (RRR). Define-se esta razão como a probabilidade de dado evento ocorrer, em relação a outro. Para tanto, considerando $P_{j}$ a probabilidade de ocorrência do evento, e $1-P_{j}$ a probabilidade de não ocorrência, a razão de chances a favor de o evento ocorrer é dada pelo quociente:

$\frac{P_{j}}{1-P_{j}}$

\footnotetext{
$\overline{7}$ Para mais informações, ver Silva, Pessoa e Lila (2002).

${ }^{8}$ Para mais informações, ver Greene (2003, p. 722).
} 
Com a transformação do logit, a expressão (6) passa a ser conhecida como antilog do logit. Esta interpretação é idêntica à do logit binário. A interpretação de variáveis quantitativas é feita pelo incremento de uma unidade e pela comparação da categoria analisada com a categoria base. Já a interpretação para uma variável categórica é dada pela relação de uma categoria com a outra (MENDONÇA et al., 2012).

A razão de chances no modelo multinomial logit é definida por:

$$
R R R=\frac{\frac{\operatorname{Prob}(Y=j / x+1)}{\operatorname{Prob}(Y=k / x+1)}}{\frac{\operatorname{Prob}(Y=j / x)}{\operatorname{Prob}(Y=k / x)}}
$$

Segundo Powers e Xie (2000), o conceito de risco relativo assemelha-se ao de odds ratio, sendo o risco definido como a probabilidade de ocorrência de determinado evento em um intervalo de tempo. Visando facilitar sua interpretação, a odds ratio pode ser convertida em incremento percentual, conforme a expressão (8), com o resultado representando a probabilidade de mudança da categoria base para a categoria em análise como fruto de variações das características dos indivíduos.

(odds - 1)·100

Constata-se que o plano amostral adotado na PNAD é complexo, sendo formado por um processo de seleção da amostra que é executado envolvendo peso amostral, estratificação, conglomeração e probabilidades díspares de seleção (IBGE, 2013b). Para análise dos dados provenientes de processos de seleção amostral desta natureza, foram utilizados o Stata 13 (StataCorp, 2013a) e o seu comando survey. ${ }^{9}$ Neste trabalho, no intuito de destacar a importância de serem consideradas as características do plano amostral, foram calculadas as medidas MEFF para cada uma das variáveis apreciadas.

\section{Resultados}

\section{Análise descritiva dos dados}

Antes de expor os resultados obtidos com a aplicação do modelo logit multinomial, as estatísticas descritivas das variáveis utilizadas podem ser visualizadas nas Tabelas 1 e 2. Notam-se distinções relativas à ocupação dos jovens residentes nas duas regiões estudadas. Enquanto no Nordeste quase $46 \%$ dos jovens ainda não haviam buscado emprego, no Sudeste este número reduzia-se para pouco menos de $39 \%$. Tal diferença reflete-se na quantidade de jovens que buscaram e obtiveram emprego, uma vez que, no Nordeste, estes eram pouco mais de $45 \%$, enquanto no Sudeste ultrapassavam os $51 \%$. Porém, em termos de jovens ativos e desempregados, nota-se semelhança entre as duas regiões, com valores

\footnotetext{
${ }^{9}$ Mais informações sobre a operacionalização deste comando e a aplicação da metodologia proposta neste artigo podem ser obtidas em StataCorp (2013b).
} 
em torno de $9 \%$, revelando semelhança, em termos numéricos, quanto à desocupação da população analisada.

TABELA 1

Distribuição dos jovens de 15 a 24 anos, segundo variáveis selecionadas Regiões Nordeste e Sudeste do Brasil - 2012

\begin{tabular}{|c|c|c|c|c|}
\hline \multirow{2}{*}{ Variáveis } & \multicolumn{2}{|c|}{ Nordeste } & \multicolumn{2}{|c|}{ Sudeste } \\
\hline & $\%$ & Erro-padrão & $\%$ & Erro-padrão \\
\hline \multicolumn{5}{|l|}{ Ocupação } \\
\hline Inativos & 0,4582 & 0,0050 & 0,3886 & 0,0048 \\
\hline Ativos e empregados & 0,4520 & 0,0048 & 0,5164 & 0,0047 \\
\hline Ativos e desempregados & 0,0899 & 0,0028 & 0,0950 & 0,0029 \\
\hline \multicolumn{5}{|l|}{ Sexo } \\
\hline Mulheres (1) & 0,5016 & 0,0039 & 0,4941 & 0,0043 \\
\hline Homens & 0,4984 & & 0,5059 & \\
\hline \multicolumn{5}{|l|}{ Raça/cor } \\
\hline Branca (1) & 0,2624 & 0,0051 & 0,4982 & 0,0061 \\
\hline Não-branca & 0,7376 & & 0,5018 & \\
\hline \multicolumn{5}{|l|}{ Situação na família } \\
\hline Chefe (1) & 0,1247 & 0,0027 & 0,1035 & 0,0026 \\
\hline Filho & 0,6225 & 0,0054 & 0,6974 & 0,0048 \\
\hline Cônjuge & 0,1264 & 0,0029 & 0,0983 & 0,0025 \\
\hline Outro & 0,1264 & 0,0032 & 0,1007 & 0,0032 \\
\hline \multicolumn{5}{|l|}{ Situação de domicílio } \\
\hline Urbano (1) & 0,7272 & 0,0092 & 0,9308 & 0,0061 \\
\hline Rural & 0,2728 & & 0,0692 & \\
\hline
\end{tabular}

Fonte: IBGE. Pesquisa Nacional por Amostra de Domicílios - PNAD 2012.

(1) Categorias bases que serão utilizadas no ajuste estatístico.

Relativamente às características demográficas, nota-se uma ligeira predominância das mulheres na composição da população jovem nordestina, sendo o contrário observado para o Sudeste. No que tange à raça/cor, grande parte dos jovens do Nordeste (74\%) se declarou não branca (pretos, pardos, amarelos, indígenas e sem declaração), em profundo contraste com a composição do contingente jovem do Sudeste, onde o número de brancos era similar ao de não brancos.

A posição do jovem em relação à pessoa de referência na família à qual pertence expressa algumas diferenças quanto às regiões analisadas. Enquanto no Nordeste a quantidade de jovens na condição de responsáveis pela família era de $12 \%$, tal proporção reduzia-se para $10 \%$ no Sudeste que, por sua vez, possuía maior parcela de jovens assumindo o papel de filhos (70\%), enquanto no Nordeste $62 \%$ estavam nesta condição. Ainda, era maior o percentual de jovens nordestinos que eram cônjuges (13\%, contra 10\% no Sudeste). Refletindo sobre estas variáveis, em conjunto, pode-se inferir por uma precocidade ligeiramente maior dos jovens do Nordeste quanto à responsabilidade que assumem perante o grupo familiar que integram. 
Nesse sentido, as heterogeneidades entre as regiões são reforçadas com os dados sobre fecundidade das jovens de 15 a 19 anos, apresentados no estudo de Cavenaghi (2013), com taxa de 81,9 nascimentos por mil mulheres nesta faixa etária no Nordeste e 54,5 nascimentos no Sudeste, em 2010. No Brasil, essa taxa estava em 69,9 nascimentos por mil mulheres neste grupo de idade. Em perspectiva, entre 2000 e 2010, a taxa de fecundidade decresceu em $28,4 \%$ no Sudeste, de forma mais acentuada do que no Nordeste, onde a queda foi de $23,7 \% .^{10}$

Com relação à última variável considerada no estudo, apresentada na Tabela 1, o local de moradia de $93 \%$ dos jovens no Sudeste era o meio urbano, diferentemente do Nordeste, onde este percentual chega a $73 \% .{ }^{11}$ A situação de domicílio dos jovens pode influenciar a empregabilidade de diversas formas. Por exemplo, autores como Silva e Kassouf (2002) e Mendonça et al. (2012) acreditam haver maior precocidade no acesso ao mercado de trabalho nas áreas rurais. A endogenia do ingresso na atividade rural familiar, como descrito por Brumer (2007), pode ser uma das explicações acerca deste processo.

A Tabela 2 contém as estatísticas descritivas das variáveis contínuas consideradas neste estudo. 0 baixo valor médio para a experiência de trabalho, em torno de um ano, reflete a faixa etária dos investigados. Entretanto, a diferença de tempo de experiência notada entre os jovens das regiões consideradas (um ano no Nordeste e dez meses no Sudeste) pode refletir a situação de domicílio dos mesmos, visto que os maiores valores encontrados para a variável experiência concentram-se entre os jovens que residiam na zona rural.

TABELA 2

Médias e erros-padrão da duração da participação no mercado de trabalho (experiência), número de componentes na família, rendimento total familiar per capita e anos completos de escolaridade dos jovens de 15 a 24 anos Regiões Nordeste e Sudeste do Brasil - 2012

\begin{tabular}{lcccccc}
\hline \multirow{2}{*}{ Variáveis } & \multicolumn{2}{c}{ Nordeste } & & \multicolumn{2}{c}{ Sudeste } \\
\cline { 2 - 3 } \cline { 6 - 7 } & Média & Erro-padrão & & Média & Erro-padrão \\
\hline Anos de experiência & 1,007 & 2,1668 & & 0,8146 & 1,5806 \\
Número de componentes da família & 4,4149 & 1,8505 & & 4,1307 & 1,5954 \\
Renda total per capita $(\mathrm{R} \$)$ & 449,30 & 629,39 & & 796,57 & 909,91 \\
Escolaridade (em anos) & 9,4737 & 3,1149 & & 10,4212 & 2,7213 \\
\hline
\end{tabular}

Fonte: IBGE. Pesquisa Nacional por Amostra de Domicílios - PNAD 2012.

O número médio de componentes das famílias consideradas não possui grande variação entre o Nordeste e o Sudeste, girando em torno de quatro pessoas. Entretanto, a análise do rendimento médio total per capita (renda total familiar dividida pelo número de componentes da família) evidenciou o abismo existe entre as regiões. Enquanto no

\footnotetext{
${ }^{10}$ Deve-se salientar que, apesar da menor taxa de fecundidade do Sudeste em relação ao Nordeste, esta ainda se encontra em níveis muito superiores aos encontrados em países mais desenvolvidos, considerando-se a faixa etária de 15 a 19 anos: 34 nascimentos por mil mulheres nos Estados Unidos, 7 por mil na França e 2,3 por mil na República da Coreia (CAVENAGHI, 2013).

${ }^{11}$ Considerando-se o total da população, em 2010, residiam em meio urbano, no Sudeste, 92,95\% dos habitantes, enquanto este número reduzia-se para $73,13 \%$ no Nordeste (IBGE, 2014).
} 
Sudeste este valor chegava a quase $\mathrm{R} \$ 800,00$, em média, sendo superior ao salário mínimo vigente em 2012,12 a renda familiar per capita dos jovens nordestinos não alcançava $\mathrm{R} \$ 450,00$, em média.

Atendo-se à análise do nível educacional, cabe salientar que, para o Brasil, os dados demonstram que a juventude atual tem feito maior investimento em educação formal, o que seria reflexo da demanda do mercado de trabalho por níveis de educação formal mais elevados. Em que pesem estes avanços, há desigualdades expressivas no acesso à educação (por faixa de renda, raça/cor, residência no rural/urbano e por região do país), além de problemas relativos à qualidade do sistema educacional. Um espelho desta realidade reflete as desigualdades regionais: mormente no Nordeste, mais do que em outras regiões do país, persiste uma elevada distorção idade-série, o que compromete o acesso ao ensino médio na idade adequada (CASTRO; AQUINO, 2008).

\section{Análise das razões de risco relativo na participação no mercado de trabalho}

Como evidenciado anteriormente, ao contrário de modelos como o de Mínimos Quadrados Ordinários, os coeficientes estimados pelo logit multinomial não representam diretamente os efeitos marginais na variável dependente, devido às variações nas covariáveis. Por este motivo, a exposição de tais coeficientes não possui muita utilidade e não foi feita neste trabalho. Assim, a apresentação e análise dos resultados provenientes do modelo logit multinomial foram realizadas à luz da razão de risco relativo (RRR) e dos efeitos marginais obtidos para cada uma das variáveis utilizadas.

Pela observação da Tabela 3, depreende-se que a maioria dos coeficientes RRR estimados exibiu significância estatística. É importante salientar que, conjuntamente, os coeficientes foram estatisticamente diferentes de zero, já que o valor apresentado pela estatística F, que mensura a significância global do modelo, correspondeu a 66,44, para o modelo referente ao Nordeste, e 70,50, para o Sudeste.

As estimativas do efeito do plano amostral indicam que sua correta consideração é essencial para obtenção de estimativas robustas e não viciadas. Nos modelos, praticamente todas as estimativas MEFF (Misspecification Effect) ${ }^{13}$ apresentaram-se superiores a 1 , indicando que, caso a amostra complexa fosse considerada aleatória simples, as variâncias das estimativas dos coeficientes seriam subestimadas. Em síntese, a estimação das razões de risco relativo permite verificar, dadas as mudanças das covariáveis, as chances que os jovens incluídos no estudo têm de pertencer à categoria inativa (categoria base) ou às demais categorias: ativo e empregado; e ativo e desempregado.

\footnotetext{
12 De acordo com o estabelecido pelo Decreto da Presidência da República no 7.655, de 23 de dezembro de 2011, o valor do salário mínimo brasileiro, em 2012, era de R\$ 622,00 (BRASIL, 2011).

${ }^{13}$ Esta medida avalia a tendência de um estimador usual (consistente), calculado sob hipótese de serem independentes e identicamente distribuídas (IID), em subestimar ou superestimar a variância verdadeira do estimador pontual (LEITE; SILVA, 2002). Para mais detalhes, ver Skinner, Holt e Smith (1989).
} 
TABELA 3

Estimativas da Razão de Risco Relativo (RRR) e efeito do plano amostral (MEFF) para situação de participação no mercado de trabalho (1) para os jovens de 15 a 24 anos Regiões Nordeste e Sudeste do Brasil - 2012

\begin{tabular}{|c|c|c|c|c|c|c|}
\hline \multirow{2}{*}{$\begin{array}{c}\text { Participação no } \\
\text { mercado de trabalho e } \\
\text { covariáveis }\end{array}$} & \multicolumn{3}{|c|}{ Nordeste } & \multicolumn{3}{|c|}{ Sudeste } \\
\hline & RRR & $\begin{array}{c}\text { Erro- } \\
\text { padrão }\end{array}$ & MEFF & RRR & $\begin{array}{c}\text { Erro- } \\
\text { padrão }\end{array}$ & MEFF \\
\hline \multicolumn{7}{|l|}{ Ativo e empregado } \\
\hline Sexo (homens) & $2,5245^{\star \star \star}$ & 0,1268 & 1,3858 & $1,7409^{\star \star \star}$ & 0,0777 & 0,9904 \\
\hline Raça/cor (brancos) & $0,8939^{\star \star}$ & 0,0415 & 1,0606 & $0,7213^{\star \star \star}$ & 0,0328 & 1,0666 \\
\hline Filho & $0,1909^{\star \star \star}$ & 0,0138 & 0,9681 & $0,1568^{\star \star \star}$ & 0,0161 & 1,2863 \\
\hline Cônjuge & $0,3150^{\star \star \star}$ & 0,0268 & 0,9315 & $0,2486^{\star * \star}$ & 0,0320 & 1,3958 \\
\hline Outro & $0,2386^{\star \star \star}$ & 0,0225 & 1,2065 & $0,2435^{\star \star \star}$ & 0,0304 & 1,3877 \\
\hline $\begin{array}{l}\text { Situação de domicílio } \\
\text { (urbano) }\end{array}$ & $1,0794 \mathrm{~ns}$ & 0,0635 & 1,2592 & $0,8858 \mathrm{~ns}$ & 0,0766 & 0,9653 \\
\hline Experiência & $2,1522^{\star \star \star}$ & 0,4467 & 5,2892 & $15,1133^{\star \star \star}$ & 6,4745 & 3,6066 \\
\hline Escolaridade & $1,0777^{\star \star \star}$ & 0,0106 & 1,6809 & $1,1582^{\star \star \star}$ & 0,0133 & 1,4709 \\
\hline Esco. x Expe. & $1,0645^{\star \star \star}$ & 0,0254 & 5,9371 & $0,9451 \mathrm{~ns}$ & 0,0338 & 3,1142 \\
\hline Com. família & $1,0562^{\star \star \star}$ & 0,0136 & 1,1497 & $1,1138^{\star \star \star}$ & 0,0166 & 1,0582 \\
\hline Renda & $1,4558^{\star \star \star}$ & 0,0401 & 1,8586 & $1,4963^{\star \star \star}$ & 0,0461 & 2,0501 \\
\hline \multicolumn{7}{|l|}{ Ativo e desempregado } \\
\hline Sexo (homens) & $1,6002^{\star \star \star}$ & 0,1092 & 1,4232 & $1,1566 * \star$ & 0,0763 & 1,1152 \\
\hline Raça/cor (brancos) & $0,7800^{\star \star \star}$ & 0,0578 & 1,4056 & $0,7649^{\star \star \star}$ & 0,0506 & 1,1610 \\
\hline Filho & $0,6962^{\star \star \star}$ & 0,0758 & 1,1856 & $0,5541^{\star \star \star}$ & 0,0699 & 1,0867 \\
\hline Cônjuge & 0,7343 ** & 0,0980 & 1,2772 & $0,5147^{\star \star \star}$ & 0,0860 & 1,2421 \\
\hline Outro & $0,7145^{\star \star \star}$ & 0,0915 & 1,2081 & $0,4798^{\star \star \star}$ & 0,0722 & 1,0826 \\
\hline $\begin{array}{l}\text { Situação de domicílio } \\
\text { (urbano) }\end{array}$ & $2,3374^{\star \star \star}$ & 0,2462 & 1,5037 & $1,6994^{\star \star \star}$ & 0,2662 & 1,1277 \\
\hline Experiência & $1,4274 \mathrm{~ns}$ & 0,3475 & 2,7559 & $6,8595^{\star \star \star}$ & 3,3795 & 2,9366 \\
\hline Escolaridade & $1,1505^{\star \star \star}$ & 0,0156 & 1,6843 & $1,1429^{\star \star \star}$ & 0,0179 & 1,4360 \\
\hline Esco. x Expe. & 1,0078 ns & 0,0279 & 3,4226 & $0,9173 * \star$ & 0,0397 & 2,7831 \\
\hline Com. família & $0,9446^{\star \star \star}$ & 0,0196 & 1,6402 & $1,0321 \mathrm{~ns}$ & 0,0231 & 1,3833 \\
\hline Renda & $0,8580^{\star \star \star}$ & 0,0166 & 1,1303 & $0,9026^{\star \star \star}$ & 0,0181 & 1,0848 \\
\hline
\end{tabular}

Fonte: IBGE. Pesquisa Nacional por Amostra de Domicílios - PNAD 2012. Resultados da pesquisa.

(1) Categoria base: Inativo; * Significativo a $10 \%$; ** Significativo a $5 \%$; *** Significativo a $1 \%$; e ns não significativo.

Desse modo, na Tabela 3, nota-se que, quanto ao sexo dos jovens, no Nordeste a chance de os homens estarem na categoria ativo e empregado é duas vezes e meia superior à das mulheres, enquanto no Sudeste esta chance é de $74 \%$. Ainda, os jovens do sexo masculino têm suas chances de pertencer à categoria ativo e desempregado majoradas em $60 \%$ e $16 \%$, no Nordeste e Sudeste, respectivamente, quand o comparados às mulheres da categoria de inativos. Portanto, embora em ambas as regiões as mulheres jovens tenham menores chances de pertencerem às categorias ativas, estando empregadas ou procurando emprego, percebe-se maior diferenciação entre os sexos no Nordeste.

Já com relação à raça/cor dos jovens, observa-se que, no Nordeste, aqueles que se declararam brancos possuem menos $11 \%$ e $22 \%$ de chances de pertencerem, respectivamente, às categorias ativo e empregado e ativo e desempregado, comparativamente aos 
não brancos. Já no Sudeste, estes números são mais contundentes, principalmente na chance de pertencer à categoria ativo e empregado (menos 28\%). Tais resultados indicam que pode haver estímulo aos jovens brancos em permanecerem inativos e não buscarem emprego, possivelmente somente estudando, sobretudo no Sudeste.

Observando-se as variáveis binárias referentes à posição do jovem na família, em que a pessoa de referência é a categoria base, verifica-se a importância desta ${ }^{14}$ na família, mesmo que ainda com menos idade, pois assumir a posição de filho, cônjuge e outro reduz as chances de estar ativo e empregado, em comparação com a categoria base, tanto no Nordeste quanto no Sudeste. Em menor magnitude, há redução das chances de pertencer à categoria ativo e desempregado para os jovens que são filhos, cônjuges e outros, em ambas as regiões.

Com relação à situação de domicílio, notou-se, tanto no Nordeste quanto no Sudeste, que o fato de os jovens morarem no meio urbano não foi significativo para explicar as chances de estarem na categoria ativo e empregado, quando comparados àqueles que residem na área rural. Porém, chama atenção o aumento em mais de duas vezes nas chances de os jovens pertencerem à categoria ativo e desempregado, caso morem no meio urbano, comparativamente a residir no meio rural, no Nordeste. Tal fator também aumenta a possibilidade de os jovens se enquadrarem nesta categoria em quase $70 \%$ no Sudeste. A análise destes efeitos demonstra que, especialmente no Nordeste, residir no meio urbano não traz vantagens relativas à obtenção de emprego, apesar de nada se poder afirmar quanto à maior facilidade para obtenção de emprego no campo e, muito menos, sobre a qualidade desta ocupação.

Corroborando o que preconizam Silva e Kassouf (2002) com relação às variáveis experiência e escolaridade, que representam o estoque de capital humano contido em um indivíduo, estando o seu aumento associado à ampliação da produtividade e consequente elevação da probabilidade de obtenção de emprego, notou-se que incrementos nas variáveis experiência e escolaridade agiram no sentido esperado. Um ano a mais de experiência, por exemplo, aumenta, no Sudeste, em mais de 15 vezes a probabilidade de os jovens pertencerem à categoria ativo e empregado e eleva em 6 vezes a possibilidade de serem ativos e desempregados, demonstrando grande importância desta variável, mormente entre aqueles jovens que já trabalharam. Tal variável, para o Nordeste, aumenta em 2 vezes a chance de os jovens estarem empregados. Ademais, um ano adicional de estudo amplia em $8 \%$ as chances de se enquadrar na categoria ativo e empregado e em $15 \%$ na de ativo e desempregado, no Nordeste. Já no Sudeste, este ano a mais de estudo representa acréscimo de $16 \%$ nas chances de empregabilidade e de $14 \%$ na possibilidade de estar ativo e desempregado. Tais decorrências ressaltam a relevância das variáveis relacionadas ao conhecimento, notadamente no concorrido mercado de trabalho do Sudeste do país.

0 número de componentes da família foi significativo apenas para explicar as chances de o jovem estar na categoria ativo e empregado, em ambas as regiões, com aumento de

\footnotetext{
$\overline{14}$ Pessoa de referência é aquela responsável pela família, ou assim considerada pelos demais membros (IBGE, 2013b).
} 
$5,62 \%$ no Nordeste e $11,38 \%$ no Sudeste. No Nordeste esta variável estava significativamente relacionada às probabilidades de desemprego, reduzindo as chances em 5,54\%, o que evidencia uma possível tendência, em famílias maiores, de obtenção de trabalho entre os jovens.

Ainda quanto à análise da razão de risco relativo, percebe-se a importância de uma maior renda familiar nas chances de emprego dos jovens pesquisados, majorando, em ambas as regiões, em mais de $45 \%$ as possibilidades de se enquadrarem na categoria ativo e empregado e, adicionalmente, reduzindo as chances de desemprego. Assim, depreende-se o que pode caracterizar-se como um círculo vicioso no que tange à variável renda, uma vez que maiores rendimentos familiares estariam relacionados a maiores chances de obtenção de emprego, nas duas regiões analisadas.

\section{Análise dos efeitos marginais}

Adicionalmente à análise das razões de risco relativo (RRR), foram obtidos, para as Regiões Nordeste e Sudeste, os efeitos marginais de cada variável, em seus respectivos pontos médios, para as três equações, em cada região considerada: inativo, ativo e empregado e ativo e desempregado. Conforme pode ser notado pela análise da Tabela 4, a maioria dos coeficientes exibiu significância estatística.

Os efeitos evidenciaram que, para o Nordeste, caso o jovem seja do sexo masculino, tudo mais considerado constante, isto atua no sentido de diminuir a probabilidade de pertencer à categoria inativo em 18,4 pontos percentuais (p.p.), aumentando a probabilidade de estar ativo e empregado em 19,45 p.p. Comportamento semelhante desta variável foi notado para o Sudeste, apesar da menor magnitude do efeito marginal. Nesta região, ser homem reduzia a inatividade em 8,1 p.p., ao passo em que elevava as chances de empregabilidade em 10,62 p.p. Estas implicações demonstram desvantagem relativa ao sexo feminino no preenchimento das vagas existentes no mercado de trabalho, sobretudo no Nordeste, corroborando o estudo de Silva e Kassouf (2002), que evidenciaram maior acesso ao mercado de trabalho por parte dos jovens do sexo masculino. Esta realidade fica mais visível em análise realizada pela Organização Internacional do Trabalho (OIT, 2007b), constatando que, na América Latina, $72 \%$ dos 22 milhões de jovens que não estudavam nem trabalhavam eram mulheres. Essa dupla "inatividade" pode estar relacionada à maternidade precoce, que ainda é um fenômeno bastante frequente entre as jovens de baixa renda, e aos estereótipos de sexo, que atribuem às mulheres a responsabilidade principal (quando não exclusiva) pelas tarefas domésticas (COSTANZI, 2009). Entretanto, deve-se salientar que, a despeito do resultado encontrado em OIT (2007a), as mulheres brasileiras possuem, em geral, número médio de anos de estudo maior do que os homens, podendo também ser uma razão para a maior inatividade feminina, que permaneceria por mais tempo apenas estudando. ${ }^{15}$

\footnotetext{
15 Entre os jovens de 20 a 24 anos, as mulheres possuíam, em média, 9,4 anos de estudo, contra 8,8 anos dos homens (COSTANZI, 2009).
} 
TABELA 4

Efeitos marginais para as equações de inatividade, emprego e desemprego dos jovens de 15 a 24 anos Regiões Nordeste e Sudeste do Brasil - 2012

\begin{tabular}{|c|c|c|c|c|c|c|}
\hline \multirow[b]{2}{*}{ Variáveis } & \multicolumn{2}{|c|}{ Inativo } & \multicolumn{2}{|c|}{ Ativo e empregado } & \multicolumn{2}{|c|}{ Ativo e desempregado } \\
\hline & $\begin{array}{c}\text { Efeito } \\
\text { marginal }\end{array}$ & $\begin{array}{c}\text { Erro- } \\
\text { padrão }\end{array}$ & $\begin{array}{c}\text { Efeito } \\
\text { marginal }\end{array}$ & $\begin{array}{c}\text { Erro- } \\
\text { padrão }\end{array}$ & $\begin{array}{c}\text { Efeito } \\
\text { marginal }\end{array}$ & $\begin{array}{c}\text { Erro- } \\
\text { padrão }\end{array}$ \\
\hline \multicolumn{7}{|l|}{ Nordeste } \\
\hline Sexo & $-0,1838^{\star \star \star}$ & 0,0117 & $0,1945^{\star \star \star}$ & 0,0119 & $-0,0107^{\star}$ & 0,0052 \\
\hline Raça/cor & $0,0277^{\star \star \star}$ & 0,0099 & $-0,0147 \mathrm{~ns}$ & 0,0105 & $-0,0130^{\star \star}$ & 0,0050 \\
\hline Filho & $0,2907^{\star \star \star}$ & 0,0157 & $-0,3447^{\star \star \star}$ & 0,0152 & $0,0540^{\star \star \star}$ & 0,0080 \\
\hline Cônjuge & $0,2386^{\star \star \star}$ & 0,0192 & $-0,2670^{\star \star \star}$ & 0,0191 & $0,0285^{\star \star}$ & 0,0128 \\
\hline Outro & $0,2918^{\star \star \star}$ & 0,0210 & $-0,3289^{\star \star \star}$ & 0,0198 & $0,0370^{\star * \star}$ & 0,0126 \\
\hline Situação de domicílio & $-0,0341^{\star \star \star}$ & 0,0125 & $-0,0195 \mathrm{~ns}$ & 0,0140 & $0,0536^{\star \star \star}$ & 0,0064 \\
\hline Experiência & $-0,1529^{\star \star \star}$ & 0,0429 & $0,1646^{\star \star \star}$ & 0,0423 & $-0,0117$ ns & 0,0148 \\
\hline Escolaridade & $-0,0177^{\star \star \star}$ & 0,0021 & $0,0107^{\star \star \star}$ & 0,0023 & $0,0070^{\star \star \star}$ & 0,0011 \\
\hline Esco. x Expe. & $-0,0119^{\star \star}$ & 0,0049 & $0,0145^{\star \star \star}$ & 0,0047 & $-0,0026^{\star}$ & 0,0015 \\
\hline Com. família & $-0,0088^{\star \star \star}$ & 0,0027 & $0,0160^{\star \star \star}$ & 0,0029 & $-0,0072^{\star \star \star}$ & 0,0016 \\
\hline Renda & $-0,0664^{\star \star \star}$ & 0,0060 & $0,0974^{\star \star *}$ & 0,0067 & $-0,0310^{\star \star \star}$ & 0,0025 \\
\hline \multicolumn{7}{|l|}{ Sudeste } \\
\hline Sexo & $-0,0811^{\star \star \star}$ & 0,0076 & $0,1062^{\star \star \star}$ & 0,0098 & $-0,0252^{\star \star \star}$ & 0,0060 \\
\hline Raça/cor & $0,0514^{\star \star \star}$ & 0,0074 & $-0,0501^{\star \star \star}$ & 0,0091 & $-0,0013 \mathrm{~ns}$ & 0,0056 \\
\hline Filho & $0,2253^{* \star \star}$ & 0,0143 & $-0,2946^{\star \star \star}$ & 0,0156 & $0,0693^{\star \star \star}$ & 0,0083 \\
\hline Cônjuge & $0,2610^{\star \star \star}$ & 0,0290 & $-0,2851^{\star \star \star}$ & 0,0282 & 0,0241 ns & 0,0156 \\
\hline Outro & $0,2680^{\star \star \star}$ & 0,0269 & $-0,2863^{\star \star \star}$ & 0,0287 & 0,0182 ns & 0,0143 \\
\hline Situação de domicílio & $0,0091 \mathrm{~ns}$ & 0,0130 & $-0,0541^{\star \star \star}$ & 0,0163 & $0,0449^{\star \star \star}$ & 0,0091 \\
\hline Experiência & $-0,4211^{\star \star \star}$ & 0,0639 & $0,4374^{\star \star \star}$ & 0,0660 & $-0,0163 \mathrm{~ns}$ & 0,0307 \\
\hline Escolaridade & $-0,0234^{\star \star \star}$ & 0,0021 & $0,0216^{\star \star \star}$ & 0,0026 & 0,0017 ns & 0,0014 \\
\hline Esco. x Expe. & $0,0097^{\star}$ & 0,0056 & $-0,0059 \mathrm{~ns}$ & 0,0059 & $-0,0038$ ns & 0,0028 \\
\hline Com. família & $-0,0158^{\star \star \star}$ & 0,0024 & $0,0204^{\star \star \star}$ & 0,0031 & $-0,0046^{\star \star}$ & 0,0020 \\
\hline Renda & $-0,0548^{\star \star \star}$ & 0,0053 & $0,0902^{\star \star \star}$ & 0,0065 & $-0,0369^{\star \star \star}$ & 0,0029 \\
\hline
\end{tabular}

Fonte: IBGE. Pesquisa Nacional por Amostra de Domicílios - PNAD 2012. Resultados da pesquisa. Nota: * Significativo a $10 \%$; ** Significativo a 5\%; *** Significativo a 1\%; e ns não significativo.

A raça/cor dos jovens influencia da seguinte forma suas chances concernentes ao mercado de trabalho: no Nordeste, região com grande concentração de não brancos (pretos, pardos, amarelos ou indígenas), cœteris paribus, o jovem tem sua chance de ser inativo diminuída em 2,77 p.p., ao passo que aumentam suas chances de estar ativo e empregado (1,47 p.p.) e ativo e desempregado (1,3 p.p.). Estes efeitos são um pouco mais acentuados para o Sudeste, onde é quase idêntico o número de brancos e não brancos: relativamente aos brancos, os jovens não brancos têm diminuição de 5,14 p.p. na perspectiva de inatividade e acréscimo de 5,01 p.p. na possibilidade de obter emprego.

Com relação às variáveis binárias referentes à posição dos jovens na família, em relação à categoria tomada como base (chefe), os resultados sugeriram que, para o Nordeste, a probabilidade de pertencer à categoria inativo tornou-se maior para o jovem no papel de filho (29,07 p.p.), cônjuge (23,86 p.p.) ou outro (29,18 p.p.), também atuando no sentido de aumentar as chances de estarem ativos e desempregados. Comportamento similar foi 
observado para a Região Sudeste, onde ser filho, cônjuge ou outro ampliaram a chance de inatividade em 22,53 p.p., 26,10 p.p. e 26,80 p.p., respectivamente, reduzindo a probabilidade de obterem emprego. Nesse sentido, os chefes das famílias parecem beneficiar-se, perante os demais membros da família, tendo em vista a maior empregabilidade. Todavia, tal circunstância não se evidencia, necessariamente, vantajosa, pois uma das explicações para tal resultado indica que jovens de famílias ou domicílios com baixa renda per capita, que ocupam a posição de pessoas de referência, tendem a ter maior necessidade de ingressar precocemente no mercado de trabalho para contribuir com a renda familiar, tendo, portanto, maiores dificuldades para continuar os estudos. Ademais, quando na chefia da família figuram os homens, a cônjuge do sexo feminino contribui assumindo a responsabilidade pelo trabalho reprodutivo e de cuidado na esfera doméstica, o que reduz suas chances de emprego (COSTANZI, 2009).

Considerando o local onde o jovem reside (meio urbano ou meio rural), em ambas as regiões, morar na zona urbana diminui as chances de os jovens estarem ativos e desempregados, aumentando, no Sudeste (que possui alta taxa de urbanização), em 5,41 p.p. a possibilidade de estarem ativos e empregados. Os efeitos marginais ainda demonstraram que os jovens do Nordeste que habitam o meio rural têm reduzida em 3,41 p.p. a probabilidade de serem inativos. Tal resultado corrobora aquele obtido por Mendonça et al. (2012), na análise de mulheres jovens do Nordeste brasileiro. Deve-se salientar que, no meio rural, dadas as condições de recrutamento para o trabalho, geralmente, os jovens tornam-se ativos mais cedo. ${ }^{16}$

A experiência, importante variável determinante para a participação no mercado de trabalho, teve efeitos marginais, indicando que seu incremento eleva a chance de os jovens estarem na categoria ativo e empregado, notadamente no concorrido mercado da Região Sudeste, onde um ano a mais de experiência do jovem foi capaz de majorar a chance de estar ativo e empregado em 43,74 pontos percentuais, ao passo que reduz as chances de inatividade em 42,11 p.p., resultados que, segundo também comprovam Mendonça et al. (2012), confirmam a importância desta variável como determinante para o acesso ao mercado de trabalho. No Nordeste, apesar da menor magnitude dos efeitos, a variável experiência também reduz a inatividade (em 15,29 p.p.), elevando a empregabilidade (16,46 p.p.). De acordo com Silva e Kassouf (2002), dado que é natural que jovens possuam pouca experiência profissional, aqueles que tenham alguma vivência no mercado estão em vantagem em relação aos demais. Porém, em consonância com relatório da OIT (COSTANZI, 2009), o fato de tal resultado indicar o aumento da demanda por experiência profissional no mercado de trabalho acabaria, em última instância, por prejudicar os mais jovens. Todavia, a maior oportunidade aos adultos (mais experientes) do que aos jovens poderia ser contraditória com outra característica que parece estar presente no período, que é o

\footnotetext{
${ }^{16}$ Adicionalmente, segundo a estrutura ocupacional evidenciada pelo relatório da OIT (COSTANZI, 2009), 18,5\% dos jovens de 15 a 24 anos ocupados estavam no setor agrícola. Em termos de sexo, enquanto $23,4 \%$ dos jovens trabalhavam no campo, este número decrescia para $11,2 \%$, no caso das mulheres.
} 
incremento da demanda por um nível mais elevado de educação formal, favorecendo os jovens, que possuem, como já demonstrado, maior escolaridade do que os adultos. Mas é imprescindivel ponderar que um maior nível de escolaridade não será necessariamente mais valorizado no mercado de trabalho se a qualidade e a pertinência da educação estiverem em questão. Por outro lado, em geral, a maior escolaridade dos jovens é diretamente proporcional às suas exigências para a participação no mercado de trabalho. Em outras palavras, os jovens que concluem o ensino superior buscam ocupações que lhes garantam melhores condições de trabalho e renda.

A escolaridade, outra variável relevante para determinar o acesso ao mercado de trabalho, atuou de forma semelhante à experiência nas três categorias analisadas. No Nordeste, um ano a mais de escolaridade agiu no sentido de diminuir em 1,77 p.p. a probabilidade de o jovem estar inativo, elevando em 1,07 p.p. a chance de que seja ativo e empregado e em 0,7 p.p. a possibilidade de ser ativo e desempregado.

No Sudeste, os efeitos marginais para a escolaridade não são tão elevados quanto aqueles apresentados pela variável experiência. Um ano a mais de escolaridade minimizou em 2,34 p.p. a chance de inatividade e elevou em 2,16 p.p. a empregabilidade, indicando efeitos novamente superiores aos do Nordeste. Entretanto, deve-se ponderar que, entre os jovens inativos, que por vezes assim se encontram justamente por estarem em período escolar, os anos de estudos adicionais lhes proporcionarão, quando de fato forem procurar emprego, maiores chances de obtê-lo, como já demonstrado nos resultados.

Em termos das características inerentes à variável educacional, há numerosas evidências da existência de desigualdades que a permeiam, entre elas, aquelas tipicamente regionais. As Regiões Sul, Sudeste e Centro-Oeste apresentam os melhores índices. Enquanto, no Nordeste, a média de anos de estudo correspondia a 6,4 para os jovens de 15 a 17 anos, 7,5 para os de 18 e 19 anos e 7,8 para aqueles de 20 a 24 anos, no Sudeste essas mesmas cifras elevavam-se para, respectivamente, 7,7, 9,4 e 9,9 anos (COSTANZI, 2009).

Outrossim, no Brasil, há uma desigualdade educacional considerável entre os jovens que estão na área rural e aqueles da zona urbana, ${ }^{17}$ além de expressiva inferioridade, em termos de anos de estudo, da população não branca, ${ }^{18}$ fato que se busca, mais recentemente, reverter por meio de políticas sociais de afirmação das populações mais vulneráveis. Porém, quando se deseja inferir acerca das razões mais apropriadas para esclarecer a baixa magnitude da influência da educação na empregabilidade, talvez deva-se considerar aquelas pertinentes à qualidade e ao (des)incentivo ao estudo. Afinal, a frequência ao ensino médio na idade adequada abrangia menos da metade dos jovens brasileiros de 15 a 17 anos, tendo em vista que cerca de um terço ainda encontra-se no ensino fundamental, quando deveria estar no ensino médio, e cerca de $18 \%$ estão fora da escola (CASTRO; AQUINO, 2008).

\footnotetext{
${ }^{17}$ Enquanto 8,6\% e 33\% dos jovens na zona urbana tinham, respectivamente, 0 a 4, e 5 a 8 anos de estudo, tais percentuais se elevavam para $28,7 \%$ e $43,7 \%$ para a juventude no campo.

${ }^{18}$ No Brasil, apenas $7,2 \%$ dos jovens brancos tinham de 0 a 4 anos de estudo e $29,5 \%$ possuíam de 5 a 8 anos. No caso dos jovens negros, estas cifras aumentavam, respectivamente, para 16,2\% e 39,7\% (COSTANZI, 2009).
} 
Nota-se, com relação às variáveis experiência e escolaridade, para o ano em análise, e considerando os jovens brasileiros na faixa etária de 15 a 24 anos, que o mercado de trabalho valoriza mais a experiência dos jovens do que a escolaridade. Pode-se também compreender este resultado como uma tendência de redução na taxa de participação da juventude, que está relacionada, basicamente, ao declínio da participação, no mercado de trabalho, dos mais jovens (15 a 19 anos), o que é positivo e, possivelmente, está relacionado ao aumento da escolaridade e à redução do trabalho infantil. Por outro lado, esta participação aumenta entre os 20 e os 24 anos (COSTANZI, 2009). Entretanto, alguns estudos, como o de Silva (2001), destacam, ainda, atitudes preconceituosas, como a opção, por parte dos empresários, por trabalhadores adultos, que somam experiência e hábitos de trabalho mais sedimentados, o que seria mais um obstáculo aos jovens, principalmente para a obtenção do primeiro emprego.

0 aumento no número de componentes da família levou ao acréscimo na probabilidade de emprego (1,6 p.p., no Nordeste, e 2,04 p.p., no Sudeste) e redução nas chances de inatividade e desemprego, manifestando o conceito de que os jovens, muitas vezes, precisam trabalhar para auxiliar no sustento de seus lares, sobretudo aqueles que abrigam famílias mais numerosas, conforme argumentam Lima (2008) e Mendonça et al. (2012).

Em ambas as regiões analisadas, os efeitos marginais da variável renda atuaram no sentido de reduzir as probabilidades de inatividade e desemprego, elevando a possibilidade de empregabilidade dos jovens avaliados, tudo mais considerado constante, em magnitudes similares, apesar do diferencial de renda observado entre o Nordeste e o Sudeste. Tais resultados são contrários à crença mais comum de que famílias com uma renda per capita maior podem proporcionar melhores condições para que seus filhos se preparem para o mercado de trabalho, possibilitando que se dediquem aos estudos, elevando, num primeiro momento, a inatividade. Porém, Scorzafave e Menezes-Filho (2001) demonstraram que, em famílias mais abastadas, há possibilidade de contratação de babás e pagamento de creches, liberando jovens mulheres para o trabalho. Além disso, a rede de contatos proporcionada aos jovens de famílias mais ricas poderia facilitar sua participação no mercado de trabalho.

É válido salientar que, apesar de constituírem análises distintas, as razões de risco relativo e os efeitos marginais indicaram uma direção semelhante, nas Regiões Nordeste e Sudeste, com relação ao comportamento das variáveis consideradas determinantes para a situação ocupacional dos jovens brasileiros, no período examinado.

\section{Considerações finais}

Abordou-se, neste trabalho, como certas características socioeconômicas e demográficas estão associadas à empregabilidade de jovens de 15 a 24 anos, nas Regiões Nordeste e Sudeste do Brasil. Por meio das apreciações feitas, considerando os resultados tanto das razões de risco relativo quanto dos efeitos marginais, constatou-se que, apesar da grande 
heterogeneidade que abrange o Nordeste e o Sudeste, evidenciada pela análise descritiva das variáveis abordadas, ambas as regiões apresentaram comportamentos semelhantes com relação ao sentido das implicações destes fatores associados à inatividade, à empregabilidade e ao desemprego dos jovens.

0 incremento do estoque de capital humano, com consequências favoráveis à produtividade dos trabalhadores de ambas as regiões, configura-se como fator crucial para a empregabilidade dos jovens. Com efeito, ressaltaram-se a escolaridade e a experiência profissional como fatores que influenciam positivamente a participação no mercado de trabalho, com impactos de maior magnitude no Sudeste.

No sentido oposto, com influência negativa na probabilidade de estar empregado, ser do sexo feminino exibiu maior proeminência no Nordeste. Desse modo, nota-se a importância do capital humano na região economicamente mais dinâmica do país, cujo mercado de trabalho prioriza a formação dos jovens como requisito para sua contratação, ao passo em que se percebe, no Nordeste, um maior alijamento das mulheres das oportunidades de emprego, refletindo, muito provavelmente, a ausência mais acentuada nesta região de mecanismos efetivos para mitigação de desigualdades.

Com base neste diagnóstico, manifesta-se a necessidade de investimentos em iniciativas que priorizem a educação de qualidade, desde o ensino fundamental, possibilitando aos jovens de todas as raças/cores maior acesso ao ensino superior. A chance de adquirirem experiência profissional, por meio de ações que incentivem os empregadores a oferecerem a oportunidade do primeiro emprego aos jovens, condizentes com o objetivo do Programa Nacional de Estímulo ao Primeiro Emprego (PNPE), instituído pela Lei n. 10.748, de 22 de outubro de 2003, também mostra-se uma alternativa valiosa na busca pela redução do desemprego juvenil. Ainda nesse contexto, a educação profissional técnica tem papel relevante, oferecendo conhecimento prático, que vem sendo valorizado pelo mercado de trabalho.

Adicionalmente, campanhas educativas acerca das consequências da gravidez precoce, inserção da educação sexual integral na grade curricular das escolas, bem como políticas de planejamento reprodutivo que permitam aos jovens o acesso adequado e de qualidade aos métodos contraceptivos são extremamente importantes. Sobre esse ponto, destaca-se que, segundo Cavenaghi (2013), a porcentagem de jovens sexualmente ativas que utilizavam algum método anticonceptivo era alta tanto no Nordeste (80,4\%) quanto no Sudeste $(74,1 \%)$, em 2006, em comparação aos níveis de uso em outros países. No entanto, a eficácia do uso destes métodos não aparentava ser adequada, visto que $65,7 \%$ dos casos de gravidez dessas jovens no Nordeste e $64,9 \%$ no Sudeste foram declarados como não planejados para aquele momento ou não desejados. Adicionalmente, a provisão de uma ampla rede de creches e pré-escolas pode minimizar as atribulações ocasionadas pela presença de filhos, na participação de jovens, prioritariamente mulheres, no mercado de trabalho.

Fundamentando-se nestes intuitos, faz-se imprescindivel apoiar e desenvolver ações como a Política Nacional da Juventude, instituída por meio da Medida Provisória n. 238, de 1 으 de fevereiro de 2005, e o Programa Nacional de Inclusão de Jovens (ProJovem), tendo 
como objetivo propiciar aos jovens a conclusão do ensino fundamental, o aprendizado de uma profissão e o desenvolvimento de ações comunitárias.

Por fim, deve-se esclarecer que este estudo não visou esgotar os diferenciais nas características que influenciam a participação dos jovens do mercado de trabalho, não refletindo a realidade brasileira como um todo. Desse modo, ficam subentendidas sugestões relativas a futuras investigações que possam avançar no que diz respeito ao estudo destes determinantes.

\section{Referências}

BRASIL. Decreto n. 7.655, de 23 de dezembro de 2011. Diário Oficial (da República Federativa do Brasil), Brasília, 26 dez. 2011.

Lei n. 11.274, de 6 de fevereiro de 2006. Diário Oficial (da República Federativa do Brasil), Brasília, 7 fev. 2006.

BRUMER, A. A problemática dos jovens na pós-modernidade. In: CARNEIRO, M. J.; CASTRO, E. G. Juventude rural em perspectiva. Rio de Janeiro: MaudX, 2007.

CAMPANTE, F. R.; CRESPO, A. R. V.; LEITE, P. G. P.G. Desigualdade salarial entre raças no mercado de trabalho urbano brasileiro: aspectos regionais. Revista Brasileira de Economia, v. 58, n. 2, p. 185-210, 2004.

CASTRO, J. A.; AQUINO, L. Juventude e políticas sociais no Brasil. Brasília: Ipea, 2008 (Texto para discussão, n. 1335).

CAVENAGHI, S. Acceso a la salud sexual y reproductiva y fecundidad de las jóvenes en el Brasil: desigualdades territoriales. Notas de Población, n. 96, p. 7-52, 2013.

COSTANZI, R. N. Trabalho decente e juventude: Brasil. Brasília: OIT, 2009.

FERNANDES, R.; PICCHETTI, P. Uma análise da estrutura do desemprego e da inatividade no Brasil metropolitano. Pesquisa e Planejamento Econômico, v. 29, n. 1. p. 87-111, abr. 1999.

GENNARI, A.; ALBUQUERQUE, C. Globalização e reconfigurações do mercado de trabalho em Portugal e no Brasil. Revista Brasileira de Ciências Sociais, v. 27, n. 79, p. 65-79, jun. 2012.

GREENE, W. Econometric analysis. Englewood Cliffs: Prentice Hall, 2003.

HERINGER, R. Desigualdades raciais no Brasil: síntese de indicadores e desafios no campo das políticas públicas. Cadernos de Saúde Pública, v. 18, n. 2, p. 57-65, 2002.

IBGE - Instituto Brasileiro de Geografia e Estatística. Pesquisa Nacional por Amostra de Domicílios - PNAD 2012. Rio de Janeiro: IBGE, 2013 a.

Pesquisa Nacional por Amostra de Domicílios 2012: notas técnicas. v. 1. Rio de Janeiro: IBGE; MPOG, 2013b. Disponível em: 〈http://goo.gl/NfotCN〉. Acesso em: 27 jul. 2015.

Sinopse do Censo Demográfico 2010. Disponivel em: 〈http://www.censo2010.ibge. gov.br/sinopse/index.php?dados=8〉. Acesso em: 14 abr. 2014.

KASSOUF, A. L. 0 trabalho infantil no Brasil. 1999. 110 f. Tese (Livre Docência) - DEAS-Esalq-USP, Piracicaba, 1999.

. Wage gender discrimination and segmentation in the Brazilian labor market. Economia Aplicada, v. 2, n. 2, jun. 1998. 
LEITE, P. G. P. G.; SILVA, D. B. do N. Análise da situação ocupacional de crianças e adolescentes nas Regiões Sudeste e Nordeste do Brasil utilizando informações da PNAD 1999. Revista Brasileira de Estudos de População, v. 19, n. 2, p. 47-63, jul./dez. 2002.

LIMA, J. R. F. Efeitos da pluriatividade e rendas não agrícolas sobre a pobreza e a desigualdade rural na Região Nordeste. 2008. 157 f. Tese (Doutorado em Economia Aplicada) - Universidade Federal de Viçosa, Viçosa, MG, 2008.

MENDONÇA, G. M.; LIMA, J. E.; LIMA, J. R. F.; LÍRIO, V. S.; PEREIRA, V. F. Determinantes da inserção de mulheres jovens no mercado de trabalho nordestino. Revista de Economia do Nordeste, v. 43, n. 4, p. 161-174, 2012.

MISSIO, J. F.; VIEIRA, R. M.; IAHN, J. F. Reestruturação produtiva, plano real e mercado de trabalho: algumas considerações sobre a Região Metropolitana de Porto Alegre. Porto Alegre: [S.I.], 2008.

OIT - Organização Internacional do Trabalho. Trabalho decente e juventude: América Latina: [resumo executivo]. Brasília, 2007a.

Trabajo decente y juventud: relatório regional. Lima, 2007b.

POCHMANN, M. Situação do jovem no mercado de trabalho no Brasil: um balanço dos últimos 10 anos. São Paulo, fev. 2007.

POWERS, D. A.; XIE, Y. Statistical methods for categorical data analysis. San Diego: Academic, 2000.

SCORZAFAVE, L. G.; MENEZES-FILHO, N. A. Participação feminina no mercado de trabalho brasileiro: evolução e determinantes. Pesquisa e Planejamento Econômico, v. 31, n. 3, p. 441-478, 2001.

SILVA, N. D. V. Jovens brasileiros: o conflito entre estudo e trabalho e a crise de desemprego. 2001. 131 f. Tese (Doutorado) - Escola Superior de Agricultura “Luiz de Queiroz”/USP, Piracicaba, 2001.

SILVA, N. D. V.; KASSOUF, A. L. A exclusão social dos jovens no mercado de trabalho brasileiro. Revista Brasileira de Estudos de População, v. 19, n. 2, p. 99-115, 2002.

SILVA, P. L. do N.; PESSOA, D. G. C.; LILA, M. F. Análise estatística de dados da PNAD: incorporando a estrutura do plano amostral. Ciência \& Saúde Coletiva, v. 7, n. 4, p. 659-670, 2002.

SKINNER, C. J.; HOLT, D.; SMITH, T.M.F. Analysis of complex surveys. Chichester: John Wiley, 1989.

STATACORP. Stata: Release 13. Statistical software. College Station, TX: StataCorp LP, 2013a.

Stata Survey Data Reference Manual: Release 13. College Station, TX: StataCorp LP, $2013 b$.

\section{Sobre os autores}

Mateus de Carvalho Reis Neves é doutorando em Economia Aplicada na Universidade Federal de Viçosa (UFV), mestre em Economia Aplicada (UFV) e graduado em Gestão de Cooperativas (UFV).

Marcos Falcão Gonçalves é doutorando em Economia Aplicada na UFV, mestre em Economia Rural pela Universidade Federal do Ceará (UFC), especialista em Gestão da Inovação e Difusão Tecnológica em Arranjos Produtivos Locais pela Universidade Federal da Bahia (UFBA), especialista em Economia Financeira e Análise de Investimentos e graduado em Economia, ambos pela Universidade Estadual de Feira de Santana (UEFS). Economista do Escritório Técnico de Estudos Econômicos do Banco do Nordeste do Brasil (BNB/ETENE) e professor da Faculdade Cearense. 
João Eustáquio de Lima é pós-doutor em Métodos Quantitativos, pela University of Florida, Ph.D. em Economia Rural pela Michigan State University e mestre em Economia Rural pela Universidade Federal de Viçosa (UFV). Professor titular do Departamento de Economia Rural da UFV.

\title{
Endereço para correspondência
}

\author{
Mateus de Carvalho Reis Neves \\ Departamento de Economia Rural \\ Avenida Purdue, s/no, campus universitário - Edifício Edson Potsch Magalhães \\ 36570-900 - Viçosa-MG, Brasil \\ Marcos Falcão Gonçalves \\ Escritório Técnico de Estudos Econômicos do Banco do Nordeste do Brasil \\ Av. Doutor Silas Munguba, 5.700, Bloco A2 térreo, Bairro Passaré \\ 60743-902 - Fortaleza-CE, Brasil \\ João Eustáquio de Lima \\ Departamento de Economia Rural \\ Avenida Purdue, s/no, campus universitário - Edifício Edson Potsch Magalhães \\ 36570-900 - Viçosa-MG, Brasil
}

\begin{abstract}
Different worlds and similar realities: youth employability in the Brazilian Northeast and Southeast

The focus of this paper is how certain factors influence the probability of participation into the labor market for young people, ages 15 to 24, in the Brazilian Northeast and Southeast, regions markedly different from each other, in several dimensions. To this end, it is analyzed the relative risk factors and the marginal effects of a logistic function applied to the microdata from the 2012 National Household Sample Survey (PNAD). Despite the socioeconomic disparities between the two Brazilian regions, they showed similarities in the effect of determining factors on employability. It was shown that education and work experience positively influenced the incorporation of youth into the labor market, mainly in the Brazilian Southeast, where one more year of schooling increases the chance of employment in $16 \%$. Being female has a negative effect on the likelihood of employment, particularly in the Brazilian Northeast, where male youth have double chance of being employed compared to females. Yet, white youth living in the Southeast have $28 \%$ less chance of being employed compared to non-whites. These results suggest the paths that public policies could take, specific for each Brazilian region, to mitigate unemployment among young people.
\end{abstract}

Keywords: Employability. Youth. Logistic function.

\section{Resumen}

Mundos distintos y realidades semejantes: empleabilidad de los jóvenes en el Nordeste y el Sudeste de Brasil

En este artículo se aborda la forma en que ciertos factores influyen en la probabilidad de participación en el mercado de trabajo de los jóvenes de 15 a 24 años en las regiones del 
Nordeste y el Sudeste de Brasil, heterogéneas entre sí en varias dimensiones. Con este fin, se analizaron las razones de riesgo relativo y los efectos marginales resultantes de una función logística aplicada a los microdatos de la Pesquisa Nacional por Amostra de Domicílios (PNAD) de 2012. Se constató que, a pesar de las disparidades socioeconómicas de estas regiones del país, en ambas se registraron comportamientos similares respecto del efecto de los determinantes sobre la empleabilidad de los jóvenes. Se evidenció que la escolaridad y la experiencia laboral influyen positivamente en la participación en el mercado de trabajo, sobre todo en el Sudeste, donde un año de estudio o más eleva las posibilidades de estar empleado en un $16 \%$. Ser mujer tiene una relación negativa con la probabilidad de trabajar, especialmente en el Nordeste, considerando que los varones de este grupo etario tienen el doble de probabilidad de estar empleados. Además, los jóvenes blancos del Sudeste poseen un $28 \%$ menos de probabilidad de estar trabajando que los que no lo son. Estos resultados sugieren el trayecto que pueden recorrer las políticas públicas específicas para cada región que apunten a reducir el desempleo entre los jóvenes.

Palabras clave: Empleabilidad. Jóvenes. Función logística.

Recebido para publicação em 17/01/2015

Recomendado para publicação 13/07/2015

Aceito para publicação em 02/08/2015 